\title{
Global Development Goals: The Folly of Technocratic Pretensions
}

\section{Sanjay Reddy and Antoine Heuty*}

This article argues that, although effective strategic choices for achieving global development goals need to be based on assessments of the costs and benefits of alternative approaches, existing methods of arriving at such assessments are highly unreliable, in particular deriving from implausible and restrictive assumptions and often depending on data of poor quality, and on the pretence that the future can be adequately known. Such weaknesses can be mitigated, but not easily overcome, without abandoning deeply held technocratic presumptions.

Key words: Poverty, development, global development goals, Millennium Development Goals, technocracy

\section{Introduction}

This study evaluates existing analytical models used to estimate the cost of achieving the Millennium Development Goals (MDGs) - from sources including the UN Millennium Project (directed by Professor Jeffrey Sachs), the UN Development Programme, the World Bank and the Zedillo Commission (the UN's Distinguished High-Level Panel of Eminent Persons on Financing for Development). It concurs that effective strategic choice requires the assessment of the costs and benefits of alternative strategies. However, existing approaches to their identification are highly unreliable. A practical alternative to these approaches exists, namely, to reject reliance on 'technocratic' models stipulated a priori to describe the reality, and to substitute pragmatic decision-making that is periodically updated on the basis of new information and collective deliberation by local, national and world society, thus diminishing the likelihood of costly errors that arise from faulty analytical models. The costs of faulty decisions are likely to mount over the period in which they are inappropriately applied, giving rise to a case for institutional structures that incorporate flexibility and encourage learning.

\footnotetext{
* Sanjay Reddy is at the Department of Economics, Barnard College, Columbia University, 3009 Broadway Avenue, New York 10027 (sr793@columbia.edu); Antoine Heuty is a Senior Economist at Revenue Watch Institute, New York. This article overlaps in part with Reddy and Heuty (forthcoming). The authors are grateful for the research assistance of Camelia Minoiu and helpful comments from Diane Elson, Laura Reichenbach, Michael Ward, Jacques Loup, Kamal Malhotra, Joseph Lim, Mathieu Brossard, Chandrika Bahadur, David Grewal, Lynn McDonald, Guido Schmidt-Traub, Rathin Roy and Jan Vandemoortele, and from Sudhir Anand, Tony Addison, Santosh Mehrotra, Ann Pettifor, and David Sahn at a workshop in Florence and Michael Reich and Norman Daniels at a presentation at the Harvard Center for Population and Development Studies.
} 


\section{The Millennium Development Goals}

The Millennium Development Goals - global development goals to which the UN system and its member countries have committed themselves - are a set of eight specific objectives for the betterment of the human condition, including goals of poverty reduction and improvement in education, gender equality, health and environmental quality. ${ }^{1}$ Approved by the UN General Assembly in 2001, they replace various previous UN initiatives to provide time-bound and quantitative global goals to guide national and international strategies for development. They are a synthesis of the International Development Goals (IDGs) agreed upon at the UN social development conferences and global summit meetings of the 1990s and the Millennium Declaration adopted by heads of state at the Millennium Summit in New York in September 2000 (United Nations, 2000). This Declaration also introduced new objectives for halving the proportion of people suffering from hunger and without sustainable access to safe drinking water, reversing the spread of HIV/AIDS, malaria, tuberculosis and other major diseases, and improving the lives of 100 million slum dwellers. An eighth goal (to 'Develop a Global Partnership for Development') was intended to underline the need for developed countries to bring about their own policy reforms, to provide assistance to developing countries, and to support an equitable global order with regard to trade and the provision of technology (United Nations, 2001). The final declaration of the Monterrey Conference on Financing for Development held in 2002 (United Nations, 2002) emphasised the dramatic shortfall in the resources required to achieve the internationally agreed development goals, including those contained in the Millennium Declaration. The adoption by a wide range of countries and major international institutions of the MDGs as nominally shared goals has led to much work for economists in identifying possible strategies to achieve them and comparing their costs and benefits.

\subsection{Estimates of the global cost of achieving the goals}

The Report of the High-Level Panel on Financing for Development (also called the 'Zedillo Report', after the former President of Mexico who chaired the Panel), suggested that 'the cost of achieving the 2015 goals would probably be on the order of an extra \$50 billion a year' (United Nations, 2002: Technical Report, p. 16). This estimate derives from adding the costs of achieving individual goals as identified in other sources (typically produced for previous international conferences on sectoral goals) and as produced by its own ad hoc calculations. Where estimates for specific goals were altogether unavailable or unfeasible to produce, the costs were not included in the analysis. Accordingly, the figures provided in the Zedillo Report are represented as merely indicating 'the order of magnitude' of the additional funds required to achieve the Millennium Development Goals.

Subsequently, other actors, including the World Bank and the UNDP, have attempted to assess the cost of achieving the MDGs in greater detail. The World Bank's

1. Each goal is associated with specific targets, 18 in total, and each target is related to quantifiable indicators, 48 in total. See Appendix Table 1.

(C) The Authors 2008. Journal compilation (c) 2008 Overseas Development Institute.

Development Policy Review 26 (1) 
estimates (Devarajan et al., 2002) give the cost (to developed-country donors) of achieving Goal 1 (the reduction of income poverty and under-nutrition) as ranging between US\$54 and \$62 billion a year, and that of achieving the other goals (by adding existing sectoral estimates, as did the Zedillo Commission) as between US\$35 and $\$ 76$ billion per year. While stressing the rather hopeful theory that the attainment of Goal 1 will help automatically to achieve the others, the Bank argues that these two sets of figures should not be aggregated, in order to avoid 'double-counting'.

A background paper for the UNDP's Human Development Report 2003 (Pettifor and Greenhill, 2003) takes a broadly similar approach, and estimates the cost of achieving Goal 1 by attempting (as does the World Bank) to identify the investments required to generate poverty-reducing increases in output in developing countries. ${ }^{2}$ The total estimate arrived at is US\$76 billion, significantly higher than the Zedillo Report and in the upper range of the World Bank's estimates. Its sectoral estimates derive from previously published sources, as in the case of the Zedillo Commission and the World Bank.

What is the basis of these estimates (other than so much hocus pocus)? As already mentioned, all these reports draw to a significant extent on previous global cost estimates developed for individual sectors. These sectoral estimates are often of poor quality, for a variety of reasons (some of which will be considered below). Moreover, as the estimates derive from different cost concepts, they cannot usually be meaningfully added. All the reports recognise (though insufficiently) these inadequacies of the global estimates and accordingly call for country-level cost estimates of achieving the MDGs, in the belief that these will be more reliable. Such country-level cost estimation exercises have been or are being undertaken currently by the UN Development Programme, the Millennium Project and the World Bank.

\subsection{Country-level cost estimates}

The Millennium Project (an advisory body to the UN Secretary-General directed by Professor Jeffrey Sachs) has published a major report Investing in Development: A Practical Plan to Achieve the Millennium Development Goals (Millennium Project, 2005), and has prepared a number of country case studies to identify major 'interventions' required in its view to achieve the MDGs in the countries concerned. To develop its 'MDG needs assessment', the Project has relied heavily on task forces of experts which it has assembled. Its approach develops a list of technical interventions that it believes can be used to achieve the MDGs, plus investment plans which aim to attain the MDGs through these interventions (ibid: 242-3). It explicitly avoids focusing its attention on policy and institutional reforms.

The World Bank project focuses on 18 countries. ${ }^{3}$ The Bank's approach gives priority to the macroeconomic policy objectives (such as the containment of inflation,

2. Regrettably, the assumptions made regarding the growth requirements for poverty-reduction and capitaloutput ratios are not at all clear.

3. Tanzania, Uganda, Ethiopia, Mozambique, Benin, Burkina Faso, Madagascar, Mali, Mauritania; Indonesia, Vietnam; Bangladesh, Pakistan, India; Bolivia, Honduras; Albania and Kyrgyz Republic. See World Bank (2003a). 
budget deficits and current account deficits) emphasised in the Poverty Reduction Strategy previously defined by each country, and asks how, given these priorities, the MDGs can best be achieved. Since the Bank gives priority to goals other than that of achieving the MDGs, it may quite properly be objected that it is not estimating the cost of achieving the MDGs at all. One way to make sense of this approach is to interpret it as estimating the cost of achieving the MDGs, subject to the constraint that a country will adhere to the plans identified in its PRSP. Although this is a coherent exercise, it is certainly not the same as estimating the cost of achieving the MDGs as such. Recent efforts by the World Bank in this area also emphasise the elaboration of a 'general equilibrium' demand-supply framework assumed to govern the production of MDGs in each country (Bourguignon, 2004). Since the data requirements and theoretical presumptions needed in order to use a general equilibrium approach of this kind are, to say the least, considerable, such efforts should be viewed as providing a conceptual framework rather than a framework for estimating the actual impact of alternative strategies. Indeed, to the best of our knowledge no detailed cost estimates for individual countries have as yet been produced on this basis; and if they were to be, they could not be taken very seriously.

At the national level, UNDP country offices have attempted to estimate the cost of attaining the MDGs in various countries (see, for example, UNDP, 2002). The reports they have produced focus on six MDG targets, related to income poverty, primary education, child mortality, maternal health, HIV/AIDS and access to water.

\section{Importance of cost estimates in the choice of strategies}

Typically, there is more than one strategy that can plausibly be employed to achieve a goal. The comparison of strategies requires attention to relevant information, including the effectiveness with which it is likely to promote the goal, the risks attendant in pursuing the strategy and its costs.

Cost estimates play a role in arriving at an answer to two types of questions. At the risk of some oversimplification, we may regard the first as evaluative in nature and the second as strategic in nature. The central evaluative question is: should a specific end be pursued at all (given alternative ends)? The primary strategic question is: how should a specific end best be pursued (given alternative means to achieve that end)? Cost estimates play an important role in determining the relative desirability of alternative means of achieving an end, in this instance the MDGs.

\subsection{The role of aggregate cost estimates in informing the choice between objectives}

The feasibility of achieving the MDGs, given a sufficient application of resources and adequate policy and institutional reform, is not generally in doubt. ${ }^{4}$ Indeed, such an assumption underpins the different estimates of the cost of achieving the MDGs that have been put forward to date. However, much of the discussion on MDG cost estimates seems to assume that a firm commitment to achieving the MDGs does not yet

4. There are certain exceptions. See, for example, Devarajan et al. (2002).

(C) The Authors 2008. Journal compilation (c) 2008 Overseas Development Institute.

Development Policy Review 26 (1) 
exist; an implicit rationale for cost estimates is that they are needed to convince developing and developed countries that the MDGs can be achieved without undue sacrifice of other objectives. Thus there has been a desire to argue that the MDGs can be achieved with a 'reasonable' quantity of resources (for instance, for less than the $0.7 \%$ of GNP development-assistance norm that donors have previously agreed upon). This is the view stressed, for example, in the Millennium Project (2005) and in Sachs (2005). There appears to be some tension between the stress placed upon the idea that the MDGs are a firm 'commitment' of the international community and the insistence that they are easily affordable to the developed countries (and by implication worth pursuing for that reason), but this is precisely what prominent analysts have done.

\subsection{The role of aggregate cost estimates in planning to achieve an objective}

Once it has been determined that a goal is to be achieved, there remains the question of how best to achieve it. Aggregate cost estimates may be important from the standpoint of budgeting. In particular, it may be necessary to identify in advance the resources to be allocated to a specific purpose. If so, it is important to identify realistically the resources that will be required. Failure to do so may lead to the inability to make appropriate expenditures when they are required, with a resulting failure to achieve the objective.

In general, the optimal level and pattern of current consumption and investment will depend on forecasts of future income and needs. The rationale for current choices regarding the level and pattern of consumption and investment derives from the part they play in an integrated expenditure plan over a relevant budgetary period.

This role of aggregate cost estimates in budgeting to achieve the MDGs may be relevant at both the global and the national level. However, budgeting must be undertaken over a realistic period. The length of the appropriate period over which budgeting should take place will reflect the reliability of forecasts regarding future costs and resource-generation opportunities, the likelihood that new information will be revealed at different points in the future, the possibility that over time there will arise changes in priorities, and the costs of undertaking budgeting itself. The appropriate period for budgeting will vary according to context and purpose. ${ }^{5}$

\subsection{The role of disaggregated cost estimates in planning to achieve an objective}

It may be desired to achieve the MDGs with the fewest possible resources, so as to leave more for other objectives than those identified in the MDGs or beyond the thresholds defined in the MDGs, or so as to achieve the MDGs as rapidly as possible. It is necessary to identify the costs of achieving the MDGs through alternative means in order to identify the most efficient approach. Let us consider two distinct types of

5. It is interesting to note that, in the context of national development plans, it has generally been thought unrealistic to produce budgetary plans over periods longer than 5 years. 
substitution which can be used to characterise alternative approaches to achieving the MDGs:

(i) Substitution across countries. A number of the MDGs are phrased as global goals. Some, such as universal primary educational enrolment, can be achieved at the global level only if achieved in every country, whereas others, such as the halving of global poverty, could be achieved by focusing efforts in a few large countries. If the MDGs are to be pursued on an aggregate global basis, without regard to the fact that individual countries may fall severely behind in their individual attainment of the goals, then the relative cost of achieving them in different countries will be of great importance to determining the best strategy to pursue. The interpretation that the MDGs are to be attained globally, and without regard to the extent of their achievement in individual countries, is implicit in certain analyses (such as Bhalla, 2002) and not in others (for example, the country studies undertaken by international organisations).

The MDGs have most often been interpreted (in particular by Devarajan et al., 2002, UNDP and the Millennium Project) as to be achieved on a country-bycountry basis. Under such an interpretation, there is no scope for substitution across countries, and as a result information concerning the relative costs of achieving the MDGs in different countries will be of little relevance.

Which interpretation is favoured is evidently an issue of some importance, and one over which there appears to be dismayingly little consensus. We do not take a view here on what is the appropriate interpretation of these goals, but simply note that which interpretation is taken is a matter of some consequence.

(ii) Substitution across means. Within any country, the MDGs may be promoted through various means. The choice of means may be very important to enabling the MDGs to be achieved at all, let alone at the least cost and as rapidly as possible. Therefore, information on the costs of promoting the MDGs through distinct means (for example, 'interventions' and 'policies') is indispensable to developing a country-specific plan for achieving them. For instance, it may be necessary to choose between promoting school enrolment through mid-day meals schemes or through reducing the distance to school. Unsurprisingly, many recent contributions to development economics have focused on such choices among means. ${ }^{6}$

\section{Analytical requirements of a cost estimate}

A credible estimate of the cost of achieving the MDGs, within a country or globally, must involve the following tasks:

Identify the cost concept. It is necessary to conceptualise costs in some way. The cost concept (costs to whom and of what type?) needs to be specified. For instance, costs to the domestic public sector, costs to the domestic and foreign public sectors, aggregate domestic costs (to the domestic private and public sectors) and aggregate

6. For an assessment of the implications of distinct analyses of this kind for determining the cost of attaining universal primary school completion, see Glewwe and Zhao (2005). 
global costs (to the domestic and foreign private and public sectors) are each distinct cost concepts that will give rise to distinct estimates of the costs of achieving a given goal. Moreover, financial costs (at market prices), social accounting costs (at appropriate shadow prices) and opportunity costs are distinct cost concepts. These distinct concepts have often failed to be clearly differentiated in the applied literature on MDGs, although each is appropriate for a different purpose and may give rise to divergent estimates. The literature on the costs of achieving the MDGs has not focused consistently on a single cost concept, although it has had an understandable focus on costs to the public exchequer (of the developing-country government and its donors).

Accurately identify the baseline scenario. It is necessary to identify the starting point in relation to which the goal is defined. What is the initial level of each indicator (for instance, the percentage of persons suffering from hunger, or possessing an income of 'less than $\$ 1$ per day') in relation to which the goals' final targets and ongoing progress ought to be assessed?

Accurately identify the cost function. It is necessary to conceptualise the cost 'function' which describes the cost of achieving the goal to a particular extent, given relevant circumstances. The cost function is associated with a development production function which describes the development outcomes that are projected to result when specific inputs are applied in particular conditions. The outcomes can in turn be distinguished or measured in different ways, in particular either as intermediate objectives (for example, the primary school enrolment rate) or final objectives (for example, the literacy rate) which are furthered by the intermediate ones.

Specifically, we may write $\bar{Y}=F(\bar{z})=F\left(\bar{z}_{\text {inputs }}, \bar{z}_{\text {conditions }}\right)$ to describe the vector of outcomes $\bar{Y}$ that is expected to result when a particular set of background conditions, $\bar{z}_{\text {conditions }}$, are in place and a particular set of inputs, $\bar{z}_{\text {inputs }}$, are applied, to produce these outcomes through the application of a specific method (defined by the function $F$ ). Associated with this development production function is a 'dual' cost function, $c\left(\bar{p}, \bar{Y}, \bar{z}_{\text {conditions }}\right)$ describing the cost of achieving specified development outcomes, given specific background conditions and the prevailing input prices, $\bar{p}$.

Since this cost function is based on subjunctive judgments and cannot directly be observed, it is necessary to have some basis for reasonably imputing it. Typically, this imputation is disaggregated into the following elements:

Identification of unit costs. What are the observed costs of generating a unit of the desired outcome, either on average or on the margin? Where these costs are not directly observed, they may be inferred based upon experiences elsewhere.

Projection of unit costs over the coverage range. What are expected to be the costs of generating subsequent units of output, until the point that the goal is achieved? Judgments concerning the costs of producing subsequent units of output will in general be influenced by current observations of unit costs and by relevant facts about the world, including the causal process giving rise to a particular outcome. For example, there may be increasing costs of achieving certain outcomes as it becomes necessary to

7. Although the simplest and most conventional way to conceive of these prices is as a set of (fixed) scalars, they may, of course, more generally be viewed as being parametrically dependent on the development outcomes that have already been brought about or on the inputs that are applied. For instance, it is sometimes thought that the 'scaling up' of development interventions may place upward pressure on the costs of required inputs, in which case such dependence must be noted. 
extend services to populations that are geographically or socially difficult to reach. On the other hand, positive 'network externalities' (associated, for instance, with the spread of information) may reduce the marginal cost of achieving certain goals, as they are closer to being attained. Judgments concerning the nature of the cost function will be controversial insofar as the empirical information and causal theories that they depend on are controversial. By definition, unit costs that will hold in the future cannot be observed. They must be estimated based upon present unit costs and (possibly also controversial) assumptions concerning expected technological and institutional changes.

\section{Main methodological problems}

Prevailing estimates of the cost of achieving the MDGs are subject to various criticisms. As we shall see, some recent estimates suffer from more severe problems than do others. All existing efforts to identify the cost of achieving the MDGs suffer from problems under each of the general headings that we identify below. Of course, approaches differ in the extent to which they suffer from the specific problems that we identify under these headings. We confine ourselves here to a discussion of issues that are of critical and cross-cutting concern in relation to all MDG cost estimates. We offer examples that are merely indicative. Many more can be found.

\subsection{Unjustified assumptions}

Existing national and global cost estimates are not robust to the choice of assumptions. A number of simplifying assumptions have been made in each existing study in order to make the analysis tractable. Unfortunately, these assumptions are rarely justified.

Macroeconomic assumptions. Studies vary widely in their (invariably ad hoc) assumptions concerning future growth rates of national income, future rates of tax revenue generation, and the levels of public and private financing of expenditure that may reasonably be expected. It might be added that they have often made very optimistic assumptions in this regard as compared with the historical record for the countries concerned.

These parameters are of great importance to 'closing a model' and generating a cost estimate, both because estimates of future requirements depend critically on growth assumptions and because it is usually desired to estimate the total costs to the domestic and foreign public sectors of achieving the MDGs rather than to estimate the costs to all. There is often no evident basis on which to choose between these qualitatively and quantitatively widely divergent assumptions, and thus the resulting cost estimates lack credibility.

Devarajan et al. (2002) of the World Bank note quite appropriately that 'any attempt to determine the aggregate costs of achieving the development goals is a highly speculative exercise'. Indeed, the methodology they themselves employ well illustrates how restrictive assumptions can result in erroneous estimates. Their basic method is to 'calculate the additional aid required to meet the poverty goal by estimating the additional growth required to raise average incomes by enough to reach the goal, and then estimating the additional aid required to attain that growth'. They emphasise that 
their approach is to assume that the MDGs must be met on a country-by-country basis. They state that 'Working backward from the existing poverty level and distribution of income, the average rate of growth required to reach the poverty goal in 2015 determines the amount of additional investment needed'. They have assumed (in their Appendix 2) that the income distribution will be unchanged (i.e. that growth in incomes will raise all incomes by an equal share) - a quite unreasonable assumption as recent experience in many countries demonstrates (see, for example, Cornia and Kiiski, 2001) - and estimate the additional resources required to attain the growth target by making alternative assumptions centred on historical experience concerning countries' savings rates and incremental capital output ratios.

Devarajan et al. also note that there may exist 'absorption constraints' that limit countries' capacity to use resources effectively. As a result, beyond a 'saturation point', additional resources are assumed to have zero impact. Moreover, this 'saturation point' is said to vary with the nature (or 'quality') of a country's policies and institutions. They report research that finds that 'for countries which have policies and institutions that are among the best of [those of] developing countries ... the point beyond which the growth impact is zero is reached when aid is around 30\% of GDP. By contrast, the saturation point for countries with extremely weak (sic) policies and institutions is calculated to be around 6\% of GDP' (p. 20). This inference is based on a model that is replete with conceptual problems. The notion of an 'absorption constraint' (beyond which the marginal impact of applying additional resources is presumably zero) is ill-conceived. Presumably it is believed that the so-called absorption constraint cannot itself be relieved through the appropriate application of additional resources. It is unclear what would in practice constitute an absorption constraint of this kind. The concept of an 'absorption constraint' is, however, employed extensively in the report of the Development Committee ${ }^{8}$ entitled 'Supporting Sound Policies with Adequate and Appropriate Financing," which goes even further and suggests that a rather large proportion of countries would be altogether unable to achieve the first MDG (and others), irrespective of the degree to which policies are revised and finances augmented (Development Committee, 2003: 10)! $!^{10}$

The view that policy revision (and in particular the abandonment by countries of 'bad' policies for 'good ones') can by itself lead to the substantial accomplishment of the first MDG, appears to be quite popular among some authors (see, in particular, Development Committee, 2003; Collier and Dollar, 1999, 2000). In addition to the admirable terminological clarity which these analysts bring to bear, they should perhaps also be congratulated on the unequivocal character of their analysis. Alas, there is universal agreement neither on how to classify policies as 'good' and 'bad' nor on the impact that 'good' policies have on growth. A country is identified as having 'good' policies, according to these authors, if it receives a high score on the World Bank 'Country Policy and Institutional Assessment' (CPIA). ${ }^{11}$ This measure relies on the

8. A Joint Ministerial Committee of the Boards of Governors of the World Bank and the IMF.

9. Now widely referred to as the 'Baird/Shetty report'. See for example Bourguignon (2004).

10. For example, health in Albania and Mauritania.

11. The CPIA assigns a value between 1 and 6 to capture perceived performance in 20 different respects, ranging from macroeconomic management and factor market policies to policies for social inclusion and public-sector management. 
subjective judgments of World Bank 'country specialists' and gives importance to criteria such as the presence of a 'Competitive Environment for the Private Sector' and 'Property Rights and Rule-based Governance. ${ }^{12}$ It gives equal weights to each indicator, notwithstanding the preponderance of indicators linked to economic policies and outcomes and the relatively few indicators linked to social policies and outcomes. It is unlikely that there would be universal agreement either that such criteria are appropriate for inclusion in a measure of 'good policies' (i.e. policies which have the good effects that are presumed to follow in these analyses) or on how to measure them. Importantly, the conclusion that the selected 'good policies' have good effects is seriously undermined by omitted variable biases and other econometric failings in the studies claiming to establish their centrality in producing desirable outcomes (in particular, economic growth). ${ }^{13}$ It seems imprudent for analysts to base a global cost estimate for achieving the MDGs on such controversial causal theories.

Estimates of the cost of achieving the first MDG are critically dependent on estimates of the so-called poverty-reduction elasticity of growth (i.e. the elasticity of the poverty headcount ratio with respect to per capita income). In the case of the World Bank's estimates, this is because the resources necessary to achieve the income growth required to achieve the first MDG depend on the assumed parameters. In the case of the Millennium Project's estimates, this is because the resources estimated to be available domestically to achieve the MDGs depend on the assumption that sufficient growth will take place to achieve the first MDG. ${ }^{14}$ In fact, estimates of poverty-reduction elasticities of growth vary widely according to the country, sector, and type of income. Recent literature (see, for instance, Bourguignon (2001); Farr (2001); Heltberg (2002); Kakwani and Pernia (2000); Ravallion and Datt (1999)) demonstrates that povertyreduction elasticities vary widely between countries, regions and persons. Moreover, such elasticities are not inflexible, but are rather greatly influenced by policy variables and by other human development achievements (such as literacy). This is hardly surprising, as it is well known that individual earnings capacities are deeply dependent on the possession of relevant human capabilities (or, as they are more frequently referred to in the literature, 'human capital'). Moreover, unless income distributions and growth dynamics are of a very special kind, it is necessarily true that as poverty reduction takes place, the so-called poverty-reduction elasticity of growth will also change. For these reasons, inflexible assumptions (such as the heroic assumption of Collier and Dollar (2000) and Devarajan et al. (2002) that the elasticity of the headcount ratio measure of poverty with respect to growth is everywhere -2 , or the equally implausible assumption of the Millennium Project (2004a) that this elasticity is

12. Vandemoortele (2003) stresses the subjectivity of evaluations concerning, for instance, whether a country has a distortionary minimum wage, excessive labour market regulations or too many public-sector workers (p. 14).

13. For instance, the omission of explanatory variables related to human 'capital' (such as life expectancy and school enrolment) and the structure of economies (such as dependence on primary commodity exports) can lead to biased estimates. The consequence is to attribute to 'good' policies a much larger effect than they may in fact have. See, for example, Dayton-Johnson and Hoddinott (2003).

14. It is not especially evident why it should be assumed that countries will actually attain this rate of growth. Indeed, the assumed per capita income growth rates (for example, 3.3\% per annum for Tanzania) are extremely optimistic in relation to historical levels in many countries. 
everywhere -1.4), are entirely without merit. This assumption plays a critical role in determining the Millennium Project's estimates of the aggregate economic growth and public investment that will be required to achieve the MDGs. The Project explicitly declines to use country-specific estimates of so-called poverty-reduction elasticities of growth because of the large variation between different available estimates (Millennium Project, 2004b: 19).

The macroeconomic assumptions underlying the major studies of the costs of achieving the MDGs must be seriously questioned.

Nature of production. A subtle but profound obstacle to producing estimates of the cost of achieving individual MDGs is the fact that this concept is not well-defined. The reason is that, as has been widely recognised, the distinct MDGs are likely to be 'jointly produced'. The interventions that help to promote a given MDG are very often likely also to promote other MDGs. To take just one example, better nutrition may promote the ability of children both to learn and to survive. In such circumstances, it is not feasible unambiguously to identify the cost of achieving the goals associated with education and with good health. The reason is that it is not possible to identify unambiguously the share of the cost of an intervention (serving as a joint input to more than one MDG) that should be attributed to each of the goals. Only the cost of achieving the MDGs jointly can, properly speaking, be identified. The cost of achieving individual MDGs can be specified by arbitrarily attributing the cost (or a share of the cost) of a particular input to a specific MDG. However, under this approach (which, for example, is that taken by the Millennium Project), the presumed cost of achieving the MDGs jointly (i.e. the sum total of the costs attributed to each MDG) will not equal the true cost of achieving the MDGs jointly. Existing efforts to estimate the total global cost of achieving the MDGs - which have simply added estimates of the presumed costs of achieving individual MDGs - are invalid. ${ }^{15}$ Efforts to identify the cost of achieving the MDGs jointly require an adequate understanding of the joint production function for MDGs. The requirements for understanding the causal pathways by which the MDGs are interrelated are immense and strain the limits of existing knowledge. Problems in the estimation of costs, which arise due to the presence of joint production, and which are conveniently ignored in many empirical economic analyses, cannot be ignored in the context of the MDGs, in view of the highly interdependent causal processes that are likely to underlie aggregate social and economic achievements in developing countries.

Focal decision variables. The Millennium Project Needs Assessment establishes a list of interventions required to meet each of the goals. ${ }^{16}$ These (possibly overlapping) lists identify appropriate 'interventions' ('defined broadly as the provision of goods and services as well as infrastructure') needed to meet each of the goals, and their costs. The Project's methodology distinguishes between 'policies' and 'institutions' (defined as 'means' for delivering specific interventions). Although the Project recognises the role of policies, it focuses its analytical work on interventions. However, a list of interventions, comprehensive as it may be, cannot provide an adequately sound framework for the comparison of alternative strategies to achieve the MDGs (which necessarily consist of both interventions and policies). It is clear that institutions and

15. We are grateful to Sudhir Anand for drawing our attention to this point.

16. A detailed list of these interventions is available in Millennium Project (2004b: 200-13).

(C) The Authors 2008. Journal compilation (c) 2008 Overseas Development Institute.

Development Policy Review 26 (1) 
policies in rich countries, such as the regime governing trade and capital flows, will have a significant impact on the ability of poor countries to achieve the MDGs, just as will the nature of institutions and policies in poor countries themselves. Moreover, the 'interventions' that are most effective may depend on the policies that are in place. Although the importance of the institutional and policy environment is noted in the Millennium Project's report, little attention is paid to the comparison between such environments. Claims concerning the policies and institutions that are most desirable are often presented without justification.

Estimates of unit costs. Existing methodologies for estimating the cost of achieving the major MDGs (for instance, those related to education and health) rely on the generalisation of unit cost estimates derived from quite limited evidence. A major issue concerns the accuracy of these unit cost estimates. Often, it is not made clear whether they refer to average or marginal costs, and what is their source (for example, national average data or a specific local observation that has been generalised). Estimates of marginal costs are based on assumptions regarding counterfactuals (for instance, concerning what factors are fixed and what factors are flexible in the short run). These can be specified in many different ways. The methodologies used are rarely made clear and may well be mutually incompatible.

Generalisation of unit cost estimates across countries is invariably done (for instance, by Kumaranayake et al. (2001) in their report for the Commission on Macroeconomics and Health and by recent MDG country studies) by using general purchasing power parity conversion factors, which may be based on poor underlying information in poor countries masking considerable diversity of relative prices across different types of commodities. The resulting estimates of the cost of expanding MDG achievements could be potentially quite incorrect.

Apart from the difficulties involved in generalising cost estimates across countries, recent country studies from different sources have made unit cost estimates for the extension of particular services in the same country that vary widely, in part because the appropriate accounting conventions to be applied in calculating such costs have not been clearly specified and are not agreed upon. Deficiencies in the quality of unit cost estimates can certainly be diminished over time. However, at present, these deficiencies are rather severe.

Extrapolation of unit costs. Should unit costs be taken as likely to remain fixed even as the goal is progressively attained, as is done in all the recent estimates of the cost of achieving the individual goals? There are strong a priori reasons to think that decreasing or increasing marginal costs (economies and diseconomies of scale) may play an important role in relation to the MDGs. For instance, in poor countries, those who are not already the beneficiaries of relevant services may be those who are most difficult to reach, for geographical or social reasons. The limited supply of skilled personnel and the impact of official development assistance on the exchange rate may make it increasingly costly to extend services. Contrarily, positive externalities may lower barriers to service provision as more units of a service are provided. Transformations in social norms and transmission of relevant knowledge within social networks are likely to be among the reasons for such phenomena (Foster and Rosenzweig, 2004). 
Although it is difficult to know in advance what the scale of such effects is and what form they take, it seems entirely plausible that they exist. Similarly, there are strong a priori reasons to think that there are significant complementarities between distinct MDGs. For instance, it seems likely that both greater access to safe drinking water and literacy will improve health outcomes. On the other hand, achieving certain goals may increase the cost of achieving others. For instance, reductions in child mortality will increase the school-age population and thereby increase the cost of achieving universal primary education. Similarly, pecuniary externalities associated with the achievement of a given MDG (such as the effects on wages and exchange rates mentioned above) may also raise the cost of achieving other MDGs. It is not difficult to think of these and other connections, or indeed to imagine that the magnitude of their impact may be sizeable. Such quantitative work as exists on the complementarities between distinct development achievements suggests that this is indeed the case. We may refer to such complementarities as 'economies of scope' (and their opposite as 'diseconomies').

How accurate is a cost estimate likely to be if it assumes that unit costs are fixed when (in fact) there exist economies (or diseconomies) of scope or scale? In order to answer this question, we undertook a simple numerical exercise drawing on actual data from a background paper of the Commission on Macroeconomics and Health, which appears to have played a critical role in the cost estimates of the Commission and to have influenced those of the Millennium Project. ${ }^{17}$ We report these results in an accompanying paper (Reddy and Heuty, forthcoming). For a variety of health interventions, we have inferred the unit costs of coverage extensions (i.e. the costs of expanding the percentage of the population covered by one percentage point) that are implicitly assumed in this background paper, which assumes a linear and separable cost function (i.e. that there are no economies or diseconomies of scale or scope). We have also used the actual baseline coverage levels and the targets (for 2007 and 2015) specified in the paper.

Whether the Commission's unit cost estimates are accurate is not in itself of great importance. The purpose of the exercise is merely to show that the impact of divergence from the assumption that there are no economies of scale or scope can be large over realistic coverage ranges. In particular, the numerical exercise shows that the impact of the presence of (dis)economies of scale or scope by themselves on total cost estimates is large. Moreover, the impact of the interaction of even moderate levels of (dis)economies of scale and scope is to generate truly massive discrepancies in total cost estimates. The inclusion of reasonable economies of scale and scope can lead to variation in total cost estimates of more than an order of magnitude. The conclusion we would draw is that, in the absence of greater knowledge concerning the causal processes at work, we should be wary of current cost estimates, which almost universally depend upon simple linearity assumptions (which preclude economies and diseconomies of scale) and separability assumptions (which preclude inter-goal externalities in production - economies or diseconomies of scope). Indeed, even if the assumptions were to be relaxed, the sensitivity of total cost estimates to the assumptions made should

17. In this connection, see also Sachs (2005).

(C) The Authors 2008. Journal compilation (c) 2008 Overseas Development Institute.

Development Policy Review 26 (1) 
be cause for great concern. Some of the results of these exercises are summarised in Table 1.

\section{Table 1: Total (tuberculosis treatment and malaria diagnosis) health costs in $\$$ bn (2002) per year under different assumptions concerning economies of scale and scope}

\begin{tabular}{|c|c|c|c|c|c|c|}
\hline 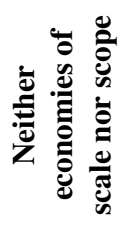 & 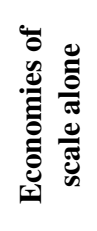 & 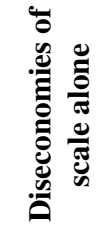 & 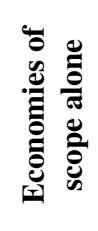 & 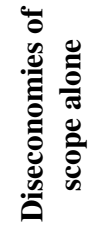 & 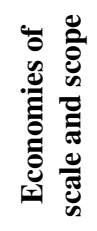 & 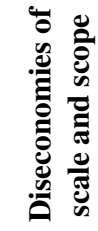 \\
\hline 4.3 & 1.442 & 17.215 & 2.213 & 6.387 & 0.737 & 25.516 \\
\hline
\end{tabular}

Notes: The results represent the values obtained for the highest and lowest magnitude of the parameters used (+/- 0/5 and +/- 1).

Figure 1 graphically demonstrates how estimates that fail to take account of economies or diseconomies of scale and scope (represented by the straight line extrapolation) can lead to potential errors in the estimation of total costs. Ex-ante, there is insufficient knowledge with which to conclude that the cost function for achieving the MDGs has a particular form. The resulting uncertainty undermines the credibility of long-range cost estimates.

\section{Figure 1: Potential error from disregarding economies of scale or scope}

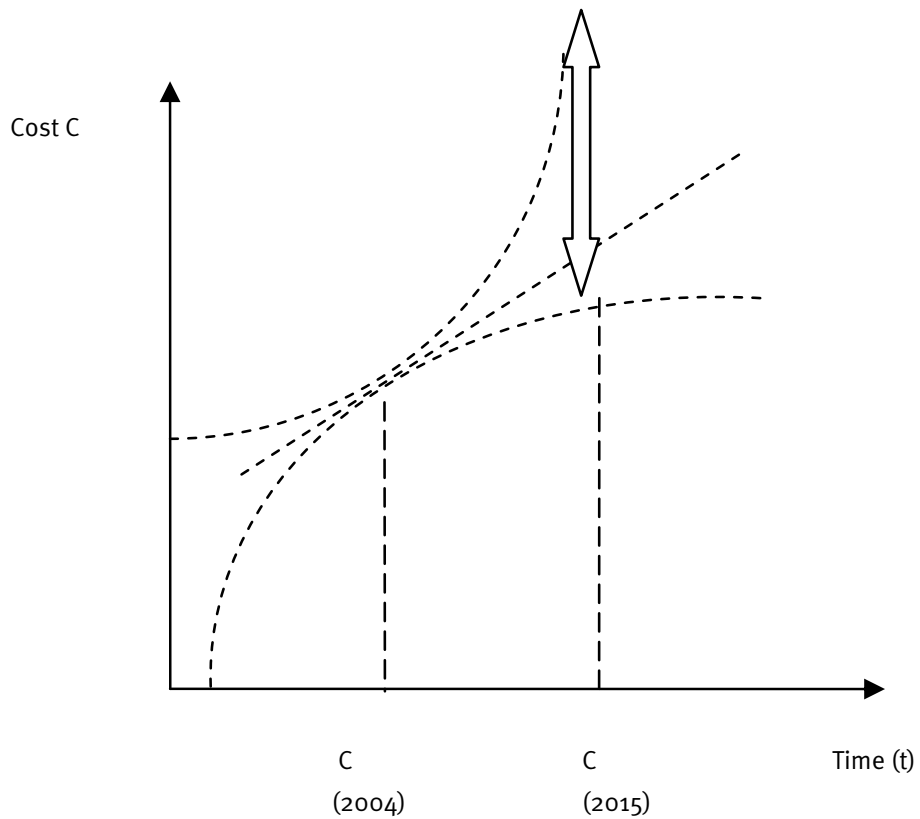

(C) The Authors 2008. Journal compilation (C) 2008 Overseas Development Institute. 
The existence of potentially large but unknown economies and diseconomies of scale and scope offers reason to doubt the credibility and accuracy of current MDG cost estimates. The World Bank (2003b: 3) acknowledges the 'inter-dependence of MDGs' without assessing - explicitly and transparently - the impact of this interdependence on the cost of achieving the MDGs. The Millennium Project makes a partial and unsatisfactory attempt to estimate complementarities between the different goals. Synergies between and within the MDGs are assessed only in the health sector - where most complementarities are assumed to occur (Millennium Project, 2004a: 24) - and 'estimated' (by what means is unclear) to 'have the potential to save 20-35 per cent of the total health costs' (ibid: 105). The Project forcefully insists that 'our treatment of synergies is not comprehensive, but we feel confident that our analysis captures some of the most important savings that can be realised by 2015 through implementing an integrated package of interventions' (ibid: 24-5).

\subsection{Weaknesses in data}

The data required to assess the baseline scenario of the MDGs and to monitor their progress over time are at present severely deficient. As a result, it is often not possible meaningfully to judge either the extent of progress required or the costs of achieving progress. A recent study published in Nature (Snow et al., 2005) found that the number of malaria cases worldwide may be close to double that previously estimated by the World Health Organisation. It points out that WHO relies heavily on clinical reports of the disease for its statistics, while many sufferers do not seek treatment. Apparent spatial and temporal variation in data is often not meaningful; consequently efforts to identify the sources of this variation and estimate relevant parameters (such as so-called 'poverty-reduction elasticities of growth') ${ }^{18}$ are also not meaningful. Estimates of unit costs (whether of providing interventions or of achieving outcomes) are rare, and where available are produced using methodologies that are most often both inadequately described and not comparable across countries. There is widespread confusion as to whether the unit costs being used refer to average or marginal costs, and there are rarely careful attempts to distinguish between these.

Identifying the joint production function for the MDGs (i.e. the determination of the impact that interventions have on outcomes) requires econometrically estimating the parameters of a rather complex and interdependent ('simultaneous equation') system. The number and complexity of the causal inter-linkages that are present between distinct MDGs as well as the uncertainties concerning these relationships and the underlying data make this task of 'identification' a difficult one, to say the least, and subject to uncertainties sufficient to raise serious doubts about the credibility of the exercise.

Weaknesses in the database for defining and monitoring the goals are most evident in regard to the first goal. Although the goal contains two components, in practice there has been a tendency to focus on the first component (halving from 1990 levels the proportion of people whose income is less than $\$ 1$ per day). Regrettably, this indicator lacks credibility. There is no convincing way in which to monitor this indicator over

18. i.e. elasticities of the poverty headcount ratio with respect to per capita income.

(C) The Authors 2008. Journal compilation (c) 2008 Overseas Development Institute.

Development Policy Review 26 (1) 
either time or space, because of basic weaknesses in its definition and its methodology of estimation. Reddy and Pogge (2003) and Pogge and Reddy (2003) have extensively discussed the difficulties involved with the ' $£ 1 /$ day' indicator of extreme poverty. There are two distinct issues here. The first is that the indicator is not meaningfully defined. The second is that it is poorly estimated.

The first concern is that the ' $\$ 1 /$ day' indicator fails meaningfully to capture extreme poverty. In a majority of poor countries, national poverty lines are substantially above ' $\$ 1 /$ day'. In fact, the ' $\$ 1 /$ day' line was not designed to capture reliably the cost of achieving any particular set of elementary human requirements. As a result, the assumption that data on ' $\$ 1 /$ day' poverty capture the reality of extreme poverty is simply false. This is an error to which the Zedillo Commission falls prey, when it writes rather casually in its technical appendix that 'It seems reasonable to suppose that extreme poverty and hunger go together; halving one would more or less halve the other'. In fact, there is no evidence of a relationship between ' $\$ 1 /$ day poverty' and other measures of human well-being, such as undernutrition (see, for example, Karshenas, 2002), and no reason to expect one.

More fundamentally and damagingly, estimates of $\$ 1 /$ day poverty for a specific country and year can fluctuate wildly due to irrelevant factors (in particular, the base year in relation to which the international poverty line is defined), undermining confidence in the meaningfulness of these estimates (Reddy and Pogge, 2003; Pogge and Reddy, 2003). Confidence in the estimates is further undermined by the fact that the PPP conversion factors used to translate the international poverty line (of $\$ 1 /$ day) into local currency units are both inappropriate (as they capture the price level of general rather than essential commodities) and are often based on an inadequate (or even altogether absent) evidence base. This is true even for large countries such as India and China which contribute a great deal to the global poverty total. Different estimates of PPPs for these countries would lead to radically different estimates of the global poverty headcount and trend. Estimates of $\$ 1 /$ day poverty do not provide a basis for meaningful comparisons of absolute poverty across time or space. As a result, the target of 'halving the proportion of people whose income is less than one dollar a day' is not well-defined, contrary to appearances. Although this is a criticism of the formulation of the first MDG, it is also a criticism of analyses that purport to identify the cost of achieving it.

The 'poverty-reduction elasticities of growth' (which specify the observed relation between the pace of economic growth and that of poverty reduction) employed by Collier and Dollar (2000), Hanmer and Naschold (2000), and the Millennium Project (2004a: Appendix 3) in the production of their cost estimates are based on these figures and therefore lack credibility. Beyond casual empiricism, there is little basis for conclusions regarding the magnitude or determinants of the elasticities of poverty indicators with respect to income. The absence of reliable and accurate estimates of 'poverty-reduction elasticities of growth' for individual countries is a reason to adopt a very sceptical view of the resulting global estimates.

The second (under-nutrition) target corresponding to the first goal is currently measured by the FAO using a 'food balance approach' that combines information on the net material balances of food available in each country with distributional assumptions concerning nutritional intake. Unfortunately, the FAO has not adopted a clear and uniform standard of under-nourishment to be applied in all countries. Also, as pointed 
out in particular by Svedberg (2001), the FAO's estimates are extremely sensitive to variations in parameter assumptions. Significant strengthening of the evidential basis for judgments concerning under-nutrition is necessary. As pointed out by Reddy and Pogge (2003), however, the strengthening of the database for the measurement of global income poverty and the database for the measurement of under-nutrition are likely to be tasks that are closely related in practice.

\subsection{Unpredictable future shocks}

Even the most carefully constructed cost estimates are unlikely ultimately to prove accurate, especially over longer time horizons. The reason is that unpredicted future shocks are eventually sure to undermine the accuracy of these estimates. The number and breadth of the assumptions required to generate global cost estimates for the MDGs all but ensure that the resulting cost estimates will eventually be made inaccurate by unpredicted shocks, operating at national or global levels, which are sure to influence both the level of achievement of the goals and the cost of extending them. Examples of significant shocks of this nature that have arisen in the past or may occur in the future include new diseases (such as HIV/AIDS), climatic events (such as the 26 December 2004 tsunami, El Niño and global warming), and various civil and regional wars. In addition to shocks of this kind that influence the aggregate cost of achieving the MDGs, unpredictable events such as shocks to terms of trade and global demand may in turn influence both the level and distribution of domestic income, and thereby influence both the total resource requirements for achieving the MDGs and the shares of these overall costs that will have to be borne by developed countries if they are to be achieved.

The impact of AIDS in Botswana provides an example of the negative consequences of an unpredicted shock. In Botswana, while life expectancy rose from 47 to 61 between 1960 and 1987, it plummeted to 39 in 2000 as a result of HIV/AIDS. The extrapolation of historical trends of life expectancy before the spread of HIV/AIDS would have led to projections of life expectancy quite at variance with the actual subsequent trend. The effects of HIV/AIDS on other human development indicators have also been significant. Unpredicted extreme events of this kind are likely to continue to arise, and will require us to show flexibility in our judgments concerning resource needs and priorities. It is important to recognise that ex-ante cost estimates based on simplified analytical models and assumed parameters are likely ultimately to prove wrong. This is a truism, but it is also more than that: it provides a note of caution in regard to technocratic exercises that are grounded in a pretension to greater knowledge, and to greater stability of the 'model' presumed to describe the world, than in fact exists.

The solutions that will be most promising are often difficult to identify in advance. It is interesting in this regard to note that many of the interventions identified by Jeffrey Sachs's Millennium Project as constituting 'quick wins' that ought to be applied widely are precisely ones whose value was widely doubted before it came to be proved through experience, and which began in localised experiments before they came to worldwide attention. For example, the value of free school meals was widely doubted when they were first introduced on a mass scale in India, as there had been a focus on the impact of such programmes on nutrition rather than on school enrolment, which proved 
subsequently to be the area in which they had the greatest impact. Similarly, the importance of eliminating user fees for basic health services was only learnt through bitter experience, as a result of the failure of World Bank, WHO and Unicef-sponsored programmes (for example, the so-called 'Bamako initiative') to introduce user fees in primary health in the 1980s and 1990s. Such programmes were touted as discouraging frivolous use of health services and raising funds for their maintenance. In fact, they discouraged many of those who most needed health services from using them. This is now universally recognised. How the conventional wisdom changes!

\section{Figure 2: The impact of HIV/AIDS on life expectancy in Botswana: historical trend and reality}

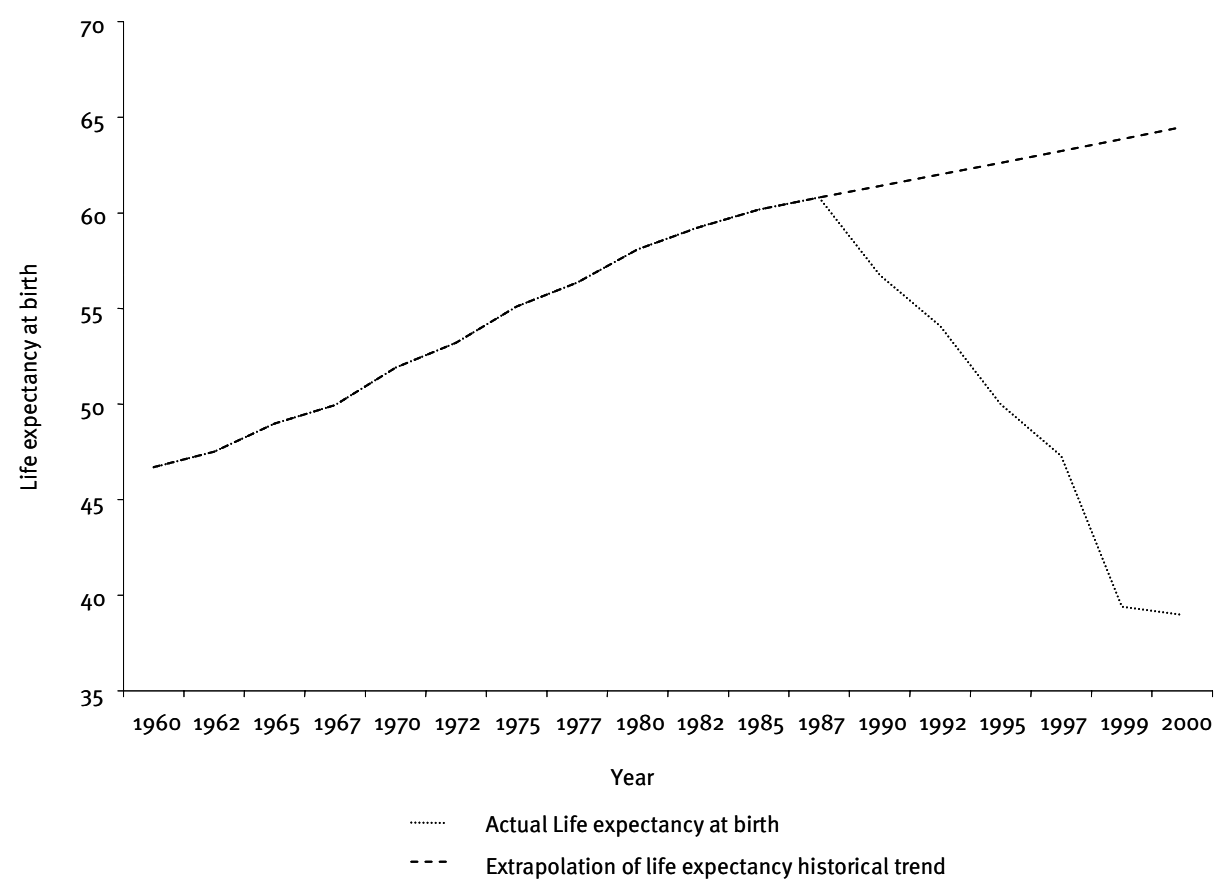

Source: World Bank (2003b).

\section{Conclusions}

It is not hard to see that damage can arise from the use of unreliable analytical frameworks in decision-making. They can lead to misallocation of resources and errors in policy choice, reducing the effectiveness of resource use, diminishing the pace with which goals are attained, or making it unfeasible for them to be attained at all. Existing approaches to identifying the best strategies for achieving the MDGs are flawed as a result of their reliance on a wide range of poorly justified assumptions, and on poor quality data. Further, their credibility rests on the empirical assumption that unpredicted 
shocks which undermine the assumptions of a given approach will be of limited importance over the time period of its application.

\subsection{Principles underlying an alternative approach}

There are some measures that can be taken to improve cost estimates, regardless of the approach used. Careful specification of cost concepts, the consistent application of a single set of accounting principles, and substantially increased investment in data collection using methods that are well-defined and stable across contexts, although unglamorous measures, are important first steps. Even with such improvements, however, some of the difficulties identified here cannot be readily overcome. By its very nature, it is difficult to know in advance whether an economy-wide developmentproduction function is likely to exhibit specific economies of scale or scope, over the large development input and outcome intervals that are involved. The properties of these functions can be reasonably judged only ex-post. ${ }^{19}$ Specific development experiences within a country and outside it may provide some information in this connection. Such information is likely to be valuable and informative but still to fall short of the rich evidential basis necessary for econometric estimation of the functional form of the development-production or cost function, in the manner that would conventionally be sought in econometric analyses of individual firms, industries or households. ${ }^{20}$ The solution cannot therefore be to seek fully to overcome the limitations in our knowledge (which are incapable of being fully overcome), but rather lies in adopting structures for decision-making which address these limitations.

The potential damage from the use of faulty analytical models as a guide to decision-making is likely to be greater when the resulting decisions are applied inflexibly over long periods of time. If these decisions are adjusted periodically in the light of new information regarding needs, options and costs, and if critical decisions are also periodically adjusted on the basis of revised cost estimates, then the damage from the use of poor analytical frameworks can be limited.

The rationale of an alternative approach is Bayesian. Its premise is that knowledge of how best to achieve the MDGs is necessarily imperfect, and evolves continually on the basis of experience. It is therefore important to avoid giving excessive weight to the imperfect knowledge available at a particular moment in time in the formation of strategic plans.

As with any objective, judgments about how best to achieve the MDGs ought to be updated in the light of new information. Strategic choices can be made more effective by seeking out and incorporating relevant information frequently and to the maximal extent, while keeping in mind the constraints imposed by the costs of forming and revising plans and actions. An alternative approach to arriving at strategies for achieving global development goals would incorporate a Bayesian insight in two ways. First, it would seek to avoid ex-ante 'one size fits all' analyses and periodically to

19. It seems that, in this mundane sphere of practical action, as in that of philosophy, the owl of Minerva spreads its wings only with the coming of the dusk.

20. Such estimation is typically thought to require adequately extensive panel data and a context of relative technological stability. 
reassess the appropriate choice of strategies in the light of new information concerning prevailing conditions and successful interventions in each country. Second, it would seek to identify appropriate strategies in light of information from other countries. In this way, the pace of learning concerning the strategies most appropriate to each country can be accelerated and the damage done by inaccurate forecasts of future opportunities and constraints in each country can be diminished. The intended consequence is to lessen the likelihood of error and to increase the likelihood of success.

There is a role for experts in the alternative approach: it is to inform decisionmakers who are empowered to synthesise available knowledge, to take account of its limitations, and to make and revise decisions accordingly. The statistical theory of decision-making suggests that the intelligent synthesis of information from multiple experts each of whose knowledge is imperfect (and who may express 'reasonable disagreement' with one another) can often lead to improved outcomes (French and Rios Insua, 2002: Chapter 4). The logic and design of a possible alternative approach employing these principles are described in an accompanying paper (Reddy and Heuty, 2005) on the application of a concept of 'peer and partner review' to the achievement of global development goals.

The supposition that solutions to complex world problems can be known in advance by a single set of technocratic experts does no service to the cause of identifying relevant and applicable actions and policies. Such solutions can only be identified in the crucible of experience.

first submitted April 2007

final revision accepted September 2007

\section{References}

Bhalla, Surjit (2002) Imagine There's No Country: Poverty, Inequality and Growth in the Era of Globalization. Washington, DC: Institute for International Economics.

Bourguignon, Francois (2004) 'An Economy-wide Framework for Monitoring the MDGs'. Presentation to Africa PREM Day, World Bank 29 April (http://siteresources.worldbank.org/INTLICUS/64137337-1094570513360/202508 02/MDGs\%20economy_wide_framework\%20Bourguignon.pdf)

Bourguignon, Francois (2001) 'The Pace of Economic Growth and Poverty Reduction'. Latin American and Caribbean Economic Association meetings in Montevideo (http://www.nip-lac.org/programs_lacea/Bourguignon.pdf).

Collier, Paul and Dollar, David (2002) 'Aid Allocation and Poverty Reduction', European Economic Review 46 (8): 1475-500.

Collier, Paul and Dollar, David (2000) 'Can the World Cut Poverty in Half? How Policy Reform and Effective Aid Can Meet International Development Goals', World Development 29 (11): 1787-802.

Cornia, Giovanni A. and Kiishi, Sampsa (2001) Trends in Income Distribution in the Post-World War II Period. World Institute for Development Economics Research (WIDER) Discussion Paper No. 2001/89. Helsinki: WIDER.

Dayton-Johnson, Jeff and Hoddinott, John (2003) Aid, Policies and Growth, Redux. Halifax, Nova Scotia: Department of Economics, Dalhousie University. 
Devarajan, Shantayanan, Miller, Eric V. and Swanson, Margaret J. (2002) Goals for Development: History, Prospects and Costs. World Bank Policy Research Working Paper No. 2819. Washington, DC: World Bank.

Development Committee, Joint Ministerial Committee of the Boards of the Bank and the Fund on the Transfer of Real Resources to Developing Countries (2003) Supporting Sound Policies with Adequate and Appropriate Financing. Washington, DC: Development Committee.

Farr, Peter (2001) 'Poverty Reduction and Economic Growth: The Asian Experience', Manila: Asia and Pacific Forum on Poverty, 5-9 February (mimeo).

Foster, Andrew D. and Rosenzweig, Mark R. (2004) 'Agricultural Productivity Growth, Rural Economic Diversity, and Economic Reforms: India, 1970-2000’, Economic Development and Cultural Change 52: 509-42.

French, Simon and Rios Insua, David (2002) Statistical Decision Theory. New York: Oxford University Press.

Glewwe, Paul and Zhao, Meng (2005) Attaining Universal Primary Completion by 2015: How Much Will It Cost? Minnesota, MN: Department of Applied Economics, University of Minnesota.

Hanmer, Lucia and Naschold, Felix (2000) 'Are the International Development Targets Attainable?', Development Policy Review 18 (1): 11-36.

Heltberg, Rasmus (2002) The Growth Elasticity of Poverty. World Institute for Development Economics Research (WIDER) Discussion Paper No. 2002/21. Helsinki: WIDER.

Kakwani, Nanak and Pernia, Ernesto (2000) Pro-Poor Growth and Income Inequality. Manila: Asian Development Bank.

Karshenas, Masood (2002) Measurement and Nature of Absolute Poverty in Least Developed Countries. Cairo: Economic Research Forum for the Arab Countries, Iran and Turkey.

Kumaranayake, Lilani, Kurowski, Christoph and Conteh, Lesong (2001) 'Costs of Scaling-up Priority Health Interventions in Low and Selected Middle-income Countries'. Background paper for Working Group 5: Improving the Health Outcomes of the Poor, Commission on Macroeconomics and Health. Geneva: World Health Organization (http://www.emro.who.int/cbi/pdf/MiddleIncomeCountries.pdf).

Millennium Project (2005) Investing in Development: A Practical Plan to Achieve the Millennium Development Goals. London: Earthscan.

Millennium Project (2004a) Millennium Development Goals Needs Assessment: Background Paper to Ending Africa's Poverty Trap. Working Paper, Millennium Project. New York: United Nations (http://www.unmillenniumproject.org/ documents/MDGneedsassessmentmethodologyNov7-04.pdf).

Millennium Project (2004b) Millennium Development Goals Needs Assessments: Country Case Studies Bangladesh, Cambodia, Ghana, Tanzania and Uganda. Working paper, Millennium Project. New York: United Nations (http://www.unmillenniumproject.org/documents/mp_ccspaper_jan1704.pdf).

Pettifor, Ann and Greenhill, Romilly (2003) 'Debt Relief and the Millennium Development Goals'. Background paper for the Human Development Report 
2003. New York: UNDP (http://hdr.undp.org/docs/publications/background _papers/2003/HDR2003_Pettifor_Greenhill.pdf).

Pogge, Thomas, and Reddy, Sanjay (2003) 'Unknown: The Extent, Distribution and Trend of Global Income Poverty'. New York: Columbia University (available at www.socialanalysis.org).

Ravallion, Martin and Datt, Gaurav (1999) When is Growth Pro-poor? Evidence from the Diverse Experiences of India's States. Policy Research Working Paper Series 2263. Wasington, DC: World Bank (http://ideas.repec.org/s/wbk/wbrwps.html).

Reddy, Sanjay and Heuty, Antoine (forthcoming) 'Global Development Goals: The Costs of Epistemic Conceit', Economic and Political Weekly, forthcoming.

Reddy, Sanjay and Heuty, Antoine (2005) 'Peer and Partner Review: A Practical Approach to Achieving the Millennium Development Goals', Journal of Human Development 6 (3): 399-420.

Reddy, Sanjay and Pogge, Thomas (2003) 'How Not to Count the Poor'. New York: Columbia University (available at www.socialanalysis.org).

Sachs, Jeffrey (2005) The End of Poverty: Economic Possibilities for Our Time. New York: Penguin Press.

Snow, Robert W.; Guerra, Carlos A.; Noor, Abdisalan M.; Myint, Hla Y. and Hay, Simon I. (2005) 'The Global Distribution of Clinical Episodes of Plasmodium falciparum Malaria', Nature 434: 214-7.

Svedberg, Peter (2001) Undernutrition Overestimated. Seminar Paper No. 693. Stockholm: Institute for International Economics Studies, Stockholm University.

United Nations (2002) Report of the International Conference on Financing for Development. Monterrey, Mexico, 18-22 March. A/CONF 198/11. New York: United Nations (http://www.un.org/esa/ffd/aconf198-11.pdf).

United Nations (2001) Road Map: Towards the Implementation of the United Nations Millennium Declaration. A/56/326. New York: United Nations (http://www.un.org/millenniumgoals/sgreport2001.pdf?OpenElement).

United Nations (2000) United Nations Millennium Declaration. A/RES/55/2. New York: United Nations (http://www.un.org/millennium/declaration/ares552e.htm).

UNDP (2002) Financing the Development Goals: An Analysis of Tanzania, Cameroon, Malawi, Uganda, and the Philippines. New York: United Nations Development Programme (http://www.undp.org/ffd/MDGfinal.pdf).

Vandemoortele, Jan (2003) 'The MDGs and Pro-poor Policies: Can External Partners Make a Difference?' (mimeo). New York: United Nations Development Group.

World Bank (2003a) Progress Report and Critical Next Steps in Scaling Up Education for All: Health, HIV/AIDS, Water and Sanitation. Washington, DC: World Bank.

World Bank (2003b) World Development Indicators 2003. Washington, DC: World Bank.

World Health Organization (2001) Macroeconomics and Health: Investing in Health for Economic Development. Report of the Commission on Macroeconomics and Health. Geneva: World Health Organization. 


\section{Appendix Table 1: The Millennium Development Goals}

Goals and targets

Goal 1: Eradicate extreme poverty and hunger

Target 1: Halve, between 1990 and 2015, proportion of people with income less than $\$ 1 /$ day

Target 2: Halve, between 1990 and 2015, the proportion of people who suffer from hunger
1. Proportion of population below $\$ 1 /$ day

2. Poverty gap ratio [incidence $\mathrm{x}$ depth of poverty]

3. Share of poorest quintile in national consumption

4. Prevalence of underweight children (under-fives)

5. Proportion below minimum dietary energy consumption

\section{Goal 2: Achieve universal primary education}

Target 3: Ensure by 2015, children everywhere, boys and girls alike, able to complete full primary schooling
6. Net enrolment ratio in primary education

7. Proportion starting grade 1 who reach grade 5

8. Literacy rate (15-24 year olds)

Goal 3: Promote gender equality and empower women

Target 4: Eliminate gender disparity in primary and secondary education preferably by 2005 and to all levels of education no later than 2015
9. Ratio girls to boys in primary, secondary and tertiary education

10. Ratio literate females to males (15-24 year olds)

11. Share of women in non-farm wage employment

12. Proportion of seats held by women in national parliament

\section{Goal 4: Reduce child mortality}

Target 5: Reduce by two-thirds, between 1990 and 2015, under-five mortality rate

13. Under-five mortality rate

14. Infant mortality rate

15. Proportion 1 year olds immunised against measles

\section{Goal 5: Improve maternal health}

Target 6: Reduce by three-quarters, between

16. Maternal mortality ratio 1990 and 2015, maternal mortality ratio

17. Proportion births attended by skilled health personnel

Goal 6: Combat HIV/AIDS, malaria and other diseases

Target 7: Have halted by 2015, and begun to reverse, spread of HIV/AIDS

Target 8: Have halted by 2015 , and begun to reverse, the incidence of malaria and other major diseases

18. HIV prevalence among 15-24 year old pregnant women

19. Contraceptive prevalence rate

20. Number of children orphaned by HIV/AIDS

21. Prevalence and death rates associated with malaria

22. Proportion in malaria risk areas using effective prevention and treatment measures

23. Prevalence and death rates associated with tuberculosis

24. Proportion TB cases detected and cured under DOTS

(Directly Observed Treatment Short Course)

\section{Goal 7: Ensure environmental sustainability}

Target 9: Integrate principles of sustainable development into country policies and programmes and reverse loss of environmental resources
25. Proportion land area covered by forest

26. Land area protected to maintain biological diversity

27. GDP per unit of energy use (proxy for efficiency)

28. Carbon dioxide emissions (per capita) [plus ozone depletion and accumulation of global warming gases] 
Target 10: Halve, by 2015, proportion without sustainable access to safe drinking water

Target 11: By 2020, have achieved significant improvement in lives of at least 100 million slum dwellers
29. Proportion with sustainable access to improved water source

30. Proportion with access to improved sanitation

31. Proportion with access to secure tenure [urban/rural disaggregation of several of above indicators may be relevant for monitoring improvement]

\section{Goal 8: Develop a global partnership for development ${ }^{\mathrm{a}}$}

Target 12: Develop further open, rule-based, predictable, non-discriminatory trading and financial system, commitment to good governance, development, and poverty reduction - nationally and internationally

Target 13: Address Special Needs of LDCs including tariff- and quota-free access for LDC exports; enhanced debt relief for HIPC and cancellation of official bilateral debt; and more generous ODA for countries committed to poverty reduction

Target 14: Address Special Needs of landlocked and small island developing countries (through Barbados Programme and 22nd General Assembly provisions)

Target 15: Deal comprehensively with debt problems of developing countries through national and international measures to make debt sustainable in long term

Target 16: In co-operation with developing countries, develop and implement strategies for decent and productive work for youth

Target 17: In co-operation with pharmaceutical companies, provide access to affordable, essential drugs in developing countries

Target 18: In co-operation with private sector, make available benefits of new technologies, especially information and communications
Some indicators below to be monitored separately for Least Developed Countries (LDCs), Africa, landlocked and small island developing countries

\section{Official Development Assistance}

32. Net ODA as percentage of DAC donors' GNP [targets of $0.7 \%$ in total and $0.15 \%$ for LDCs]

33. Proportion ODA to basic social services

34. Proportion ODA that is untied

35. Proportion ODA for environment in small island developing states

36. Proportion ODA for transport sector in land-locked countries

\section{Market access}

37. Proportion exports (by value and excluding arms) admitted free of duties and quotas

38. Average tariffs and quotas on agricultural products and textiles and clothing

39. Domestic and export agricultural subsidies in OECD countries

40. Proportion ODA provided to help build trade capacity

Debt sustainability

41. Proportion official bilateral HIPC debt cancelled

42. Debt service as percentage of exports

43. Proportion ODA provided as debt relief

44. Number of countries reaching HIPC decision and completion points

45. Unemployment rate of 15-24 year olds

46. Proportion population with access to affordable essential drugs on a sustainable basis

47. Telephone lines per 1,000 people

48. Personal computers per 1,000 people

Notes: a) The selection of indicators for Goals 7 and 8 is subject to further refinement. 
Copyright of Development Policy Review is the property of Blackwell Publishing Limited and its content may not be copied or emailed to multiple sites or posted to a listserv without the copyright holder's express written permission. However, users may print, download, or email articles for individual use. 